\title{
Friction Stir Welding of Shipbuilding Steel with Primer
}

\author{
José Azevedo ${ }^{1}$, Luísa Quintino ${ }^{1,2}$, Virginia Infante ${ }^{1,3}$, Rosa Maria Miranda ${ }^{4}$, Jorge dos Santos ${ }^{5}$ \\ 1 Universidade Técnica de Lisboa, Instituto Superior Técnico, Lisboa, Portugal. \\ 2 Instituto de Engenharia Mecânica - IDMEC, Lisboa, Portugal. \\ 3 Instituto de Ciência e Engenharia de Materiais e Superfícies - ICEMS, Lisboa, Portugal. \\ 4 Universidade Nova de Lisboa, Faculdade de Ciências e Tecnologia, Unidade de Investigação e Desenvolvimento em Engen- \\ haria Mecânica e Industrial - UNIDEMI, Departamento de Engenharia Mecânica e Industrial, Caparica, Portugal. \\ 5 Solid-State Joining Processes, Material Mechanics, Institute of Materials Research, Helmholtz-Zentrum Geesthacht, \\ Geesthacht, Germany.
}

Received: 18 Nov., 2015

Accepted: 14 Jan., 2016

E-mails: Iquintino@tecnico.ulisboa.pt (LQ)
Abstract: Friction Stir Welding has proven its merits for welding of aluminium alloys and is focused in expanding its material database to steel and titanium and also to assess new joint configurations. The use of welded structures in shipbuilding industry has a long tradition and continuously seeks for innovation in terms of materials and processes maintaining, or even, reducing costs. Several studies have been performed in the past years on FSW of steel. However, just recently were reported defect-free welds, free of martensite with stable parameters in steel without Primer. FSW of steel with primer has not been addressed. This work aims to fulfil a knowledge gap related to the use of friction stir for welding shipbuilding steel by analysing the effect of welding parameters on the metallurgical characteristics and mechanical properties of welds obtained with an innovative FSW tool in joining steel plates with a primer. Welds were performed in $4 \mathrm{~mm}$ thick GL-A36 steel plates painted with a zinc based primer followed by a detailed microscopic, chemical and mechanical analysis. The results that matching fatigue properties are obtained using this technique, in FSW of shipbuilding steel with Primer.

Key-words: Friction stir welding; Shipbuilding steel; Primer; FSW Tools.

\section{Introduction}

After the success of the introduction of friction stir welding (FSW) in industry mainly in aluminium, researchers started to study the possibility of applying FSW to other materials. Steel, is the most widely used material in metalworking industry in a wide range of applications thus, the need for research on applying FSW to this material.

Friction stir welding (FSW) was invented in the last decade of the 20th century and is nowadays considered an important milestone in the history of welding technology.

FSW is a simple ecologic and promisingly productive welding process that enables to reduce material waste and to avoid radiation and harmful gas emissions, usually associated with fusion welding processes. It is a solid-state joining process, in which the materials involved are not melted that uses a rotating tool under an axial forging force to join two faying surfaces. FSW tools are mainly constituted by a probe and a shoulder made of a hard heat resistant material. The heat generated by friction between the rotating shoulder and the material surface softens the base material in the vicinity of the tool, favouring its viscoplasticity. The tool travelling along the joint produces an intense visco-plastic deformation following quite complex paths around the tool, depending on the tool geometry, process parameters and the material to be welded. The main process parameters influencing material flow and weld quality include the tool geometry (probe and shoulder shape and relative dimensions of probe and shoulder), welding parameters (rotation to travel speed ratio, plunge depth and tilt angle), base material flow stress and temperature behaviour. The main limitation for the application of FSW in steel is the tool wear, since steel is a hard material. So, new tools are being investigated, namely with additions of tungsten and rhenium.

Thomas et al. [1] firstly showed the feasibility of FSW in low carbon steel and $12 \%$ $\mathrm{Cr}$ alloy steel welded in a single pass in thicknesses between 3 and $12 \mathrm{~mm}$. Mechanical 
properties of the welded joints could be compared with those of the base material after tensile and bending tests. The authors pointed out the tool wear as the major drawback due to tool lifetime and costs.

Lienert et al. [2] studied FSW of mild steel (hot-rolled AISI 1018). The experimental procedure included testing FSW, at different rotating and traverse speeds, and measure the temperature and force applied during the process. It was found the weld area displayed several structurally distinct regions. A stirred zone (SZ) with small grain size due to dynamic recrystallization observed after the intense plastic deformation and temperature in the range

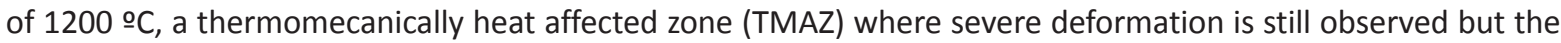
temperature is insufficient to promote recrystallization, a heat affected zone (HAZ) and finally the base material. However, in carbon steels, it was difficult to distinguish the TMAZ and HAZ unlike in Al alloys.

Reynolds et al. [3] tested FSW in a $6.4 \mathrm{~mm}$ thick DH-36 steel plate for shipbuilding industry. The results confirmed most of previous conclusions and established some of the characteristic aspects of FSW in steel, widely accepted nowadays. Reynolds was also one of the first researchers to report the existence of both martensite and bainite in the microstructure of the stirred zone, which causes a hardness increase. In this particular steel it raised from 177 to a peak of $415 \mathrm{HV}$.

Konkol et al. [4] studied FSW on a HSLA65 steel. This is one of the first reports of successful application of FSW and a full analysis of FSW joint properties was presented. HSLA-65 (or ASTM A 945) was, at the time, a new structural steel of great interest in the shipbuilding community (already a wide user of FSW for aluminum structures). Transverse tensile and bend tests, as well as hardness, ductility, toughness and corrosion tests, besides metallographic characterization, were performed in FS weldments (single pass in $6.4 \mathrm{~mm}$ thickness plates and double-pass in $12.7 \mathrm{~mm}$ plates) using argon as a shielding gas.

Other research work followed in 2009 and 2012 on mild steel and HSLA-65 confirming the ability of FSW to weld steel Failla [5], Lakshiminarayan and Balasubramanian [6].

More recently, Avila et al. [7], analysed the fracture toughness of API5LX80 steel in butt joints welded in two passes by FSW till -20 degrees with good results for pipeline applications, For shipbuilding applications McPerson et al. [8] compared fatigue behaviour of submerged arc and friction stir weld in DH36 concluding on am improved performance of the later, Azevedo et al. [9] analysed fatigue behaviour in friction stir welded 4mm thick GL-A 36 steel, while Pandley and Gupta [10] studied fatigue growth of mild steel plate welded by friction stir welding and concluded that the growth rate in the welded material is lower than in the base material. Nathan et al. [11] confirmed the superior mechanical properties in naval grade high strength alloy (HSLA) when welded with FSW in comparision with arc welding as GMA and SMA.

This short survey allows to conclude that several studies have been performed in the past years on FSW of steel. However, just recently were reported defect-free welds, free of martensite with stable parameters in steel without primer. The tool wear is still a problem for technology transfer from the laboratory to the shipbuilding industry.

This paper presents a research work aiming to contribute for the implementation of FSW in shipbuilding by analysing its performance in welding steel with a primer, since this is a common situation in shipbuilding industry.

\section{Experimental Approach}

The experimental approach consisted in performing welds in $4 \mathrm{~mm}$ steel plates with using a welding procedure which leads to sound welds, Azevedo [12], and conduct a detailed analysis of the welds obtained, based in metallographic examination, analysis of the chemical composition of the different weld zones using EDS (energy dispersive spectroscopy) and assessment of the mechanical behaviour by microhardness, tensile and fatigue testing.

\subsection{Welding equipment and friction stir welding tools}

The equipment used was a customised FSW machine (Figure 1) from Helmholtz-Zentrum Geesthacht with a rotating speed in the range of -5000 to $+5000 \mathrm{rev} / \mathrm{min}$, a maximum advancing speed of $160 \mathrm{~mm} / \mathrm{s}$, a maximum torque of $125 \mathrm{~N} . \mathrm{m}$, a working table dimensions with $2500 \times 850 \mathrm{~mm}$, with mechanical clamping systems and electric actuators . 


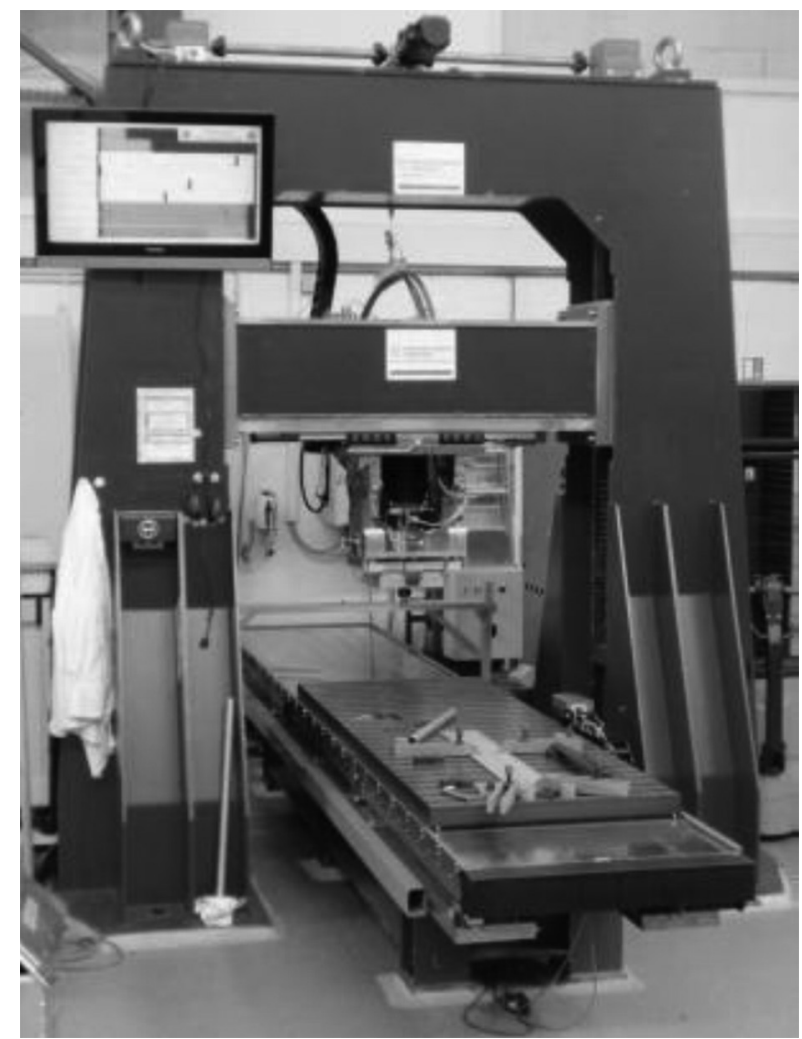

Figure 1. FS Welding machine.

The machine allows to directly monitor: time, torque, rotating speed, advancing speed in the welding direction, force in $\mathrm{X}$ and $\mathrm{Z}$ directions and movement in $\mathrm{Z}$ direction.

The tool was an innovative Tantalum based with a shape of a frustrum cone as shown in Figure 2.

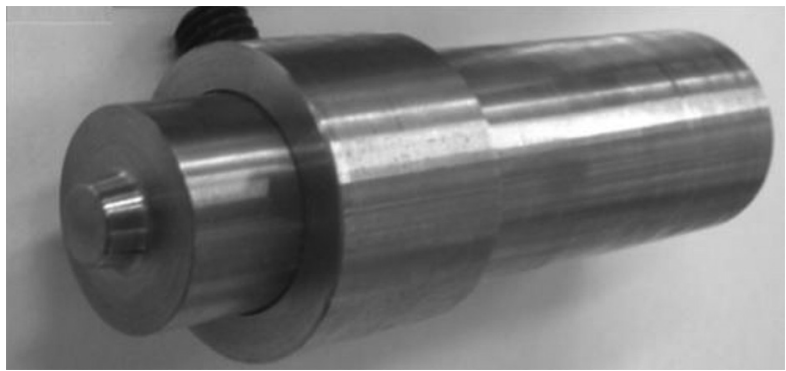

Figure 2. FSW Ta based tool.

The Tantalum tool was very recently introduced in in FSW of steel. Because of its mechanical characteristics and strength to withstand both thermal fatigue and wear, the inclusion of Tantalum in tools for FSW has been progressively taken in consideration, despite its high cost, for improved duration.

\subsection{Welding parameters and steel plates}

The welding parameters, the chemical composition of the primer and the steel plates are presented in Tables 1, 2 and 3.

The steel plate was painted with a red primer before welding. Its chemical composition is presented in Table 2.

The chemical composition of the steel used is presented in Table 3. 
Table 1. Welding parameters of the steel plates used $\left(\ell\right.$ - Thickness, $F_{z}-$ Axial force, $D-$ Rotating speed, $V-$ Transverse speed).

\begin{tabular}{|c|c|c|c|c|c|c|c|c|c|}
\hline \multirow{2}{*}{$\begin{array}{l}\text { Steel } \\
\text { Plates }\end{array}$} & \multicolumn{2}{|c|}{ Material } & \multirow{2}{*}{$\begin{array}{c}\text { D } \\
{[\mathrm{rev} / \mathrm{min}]}\end{array}$} & \multirow{2}{*}{$\begin{array}{c}\mathbf{F}_{z} \\
{\left[\mathbf{k} \mathbf{N}^{\prime}\right]}\end{array}$} & \multirow{2}{*}{$\begin{array}{c}\mathrm{V} \\
{[\mathrm{mm} / \mathrm{s}]}\end{array}$} & \multirow{2}{*}{$\begin{array}{c}\text { Tool tilt } \\
\text { Angle [०] }\end{array}$} & \multirow{2}{*}{ Tool } & \multirow{2}{*}{$\begin{array}{c}\text { Backing } \\
\text { Bar }\end{array}$} & \multirow{2}{*}{$\begin{array}{c}\text { Shielding } \\
\text { Gas }\end{array}$} \\
\hline & Ref & $\ell[\mathrm{mm}]$ & & & & & & & \\
\hline $\begin{array}{c}\text { FSW-PA- } \\
\text { LB-548 }\end{array}$ & GL-A36 & 4 & 1000 & 20 & 2 & 2 & FSW-Ta & $\begin{array}{c}\text { Steel } \\
1.6 \mathrm{~mm}\end{array}$ & $\begin{array}{c}\text { Argon } \\
\text { (50 l/min) }\end{array}$ \\
\hline
\end{tabular}

Table 2. Primer Chemical Composition.

\begin{tabular}{|c|c|c|c|c|c|c|c|}
\hline \multirow{2}{*}{ Primer } & \multicolumn{6}{|c|}{ Element (in wt \%) } & \multirow{2}{*}{$\begin{array}{r}\text { Efficiency } \\
\left(T=20^{\circ} \mathrm{C}\right)\end{array}$} \\
\hline & Al & Cd & $\mathrm{Cu}$ & $\mathrm{Fe}$ & $\mathbf{P b}$ & Zn & \\
\hline GL-Zn & $\leq 0.5$ & $\leq 0.7$ & $\leq 0.005$ & $\leq 0.005$ & $\leq 0.006$ & $\geq 99.22$ & $95 \%$ \\
\hline
\end{tabular}

Table 3. Chemical Composition of the steel plates (in wt\%).

\begin{tabular}{ccccccccccc}
\hline & \multicolumn{10}{c}{ Element } \\
FSW-PA- & $C$ & $S i$ & $M n$ & $P$ & $S i$ & $C r$ & $M o$ & $N i$ & $C u$ & $A l$ \\
LB-548 & 0.1 & 0.32 & 1.40 & $<0.010$ & $<0.010$ & 0.03 & $<0.01$ & 0.17 & 0.15 & 0.04 \\
\hline
\end{tabular}

\section{Results and Discussion}

\subsection{Metallographic analysis}

The welded joints have a very characteristic aspect showing four different regions in the macrograph: the base material (BM), the heat-affected zone (HAZ), the upper stirred zone (USZ) and the lower stirred zone (LSZ). Additionally, there is a lighter stain within the stirred zone that produced a very light microstructure. It is also observed that the total heat affected area is quite wide (influenced by both the probe and the shoulder used), increasing from the beginning to the end of the weld and from the bottom to the top through the plate thickness (Figures 3 and 4). Additionally, the differences between the advancing and the retreating sides can be identified. While the retreating side has a semi-elliptical shape with an almost constant radius, the advancing side showed always a clear inflection point in the interface, slightly below the plates' mid thickness, between the heat affected region (HAZ) and the base material (BM).

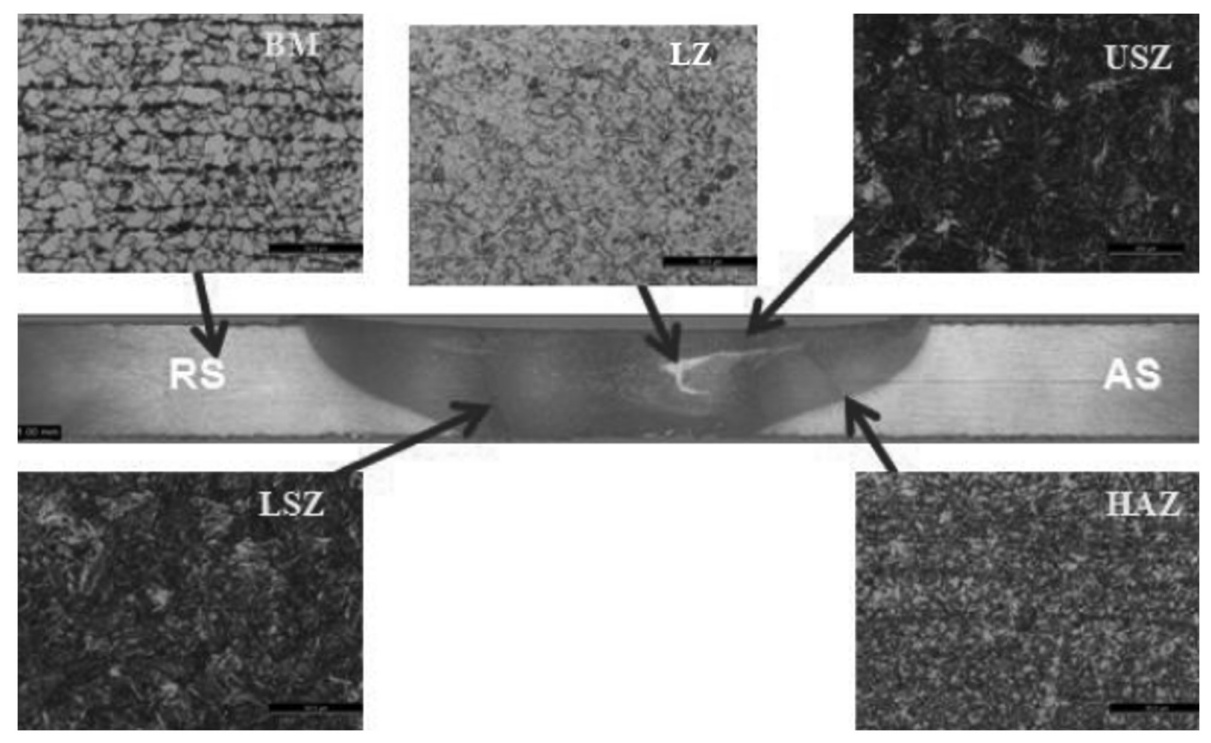

Figure 3. Macro and Micrographs of the weld FSW-PA-LB-548 at the beginning of the welding joint, BM - base material; LZ - light zone; USZ - upper stirred zone; RS - retreating side; AS - advancing side; LSZ - lower stirred zone; HAZ - heat affected zone. 


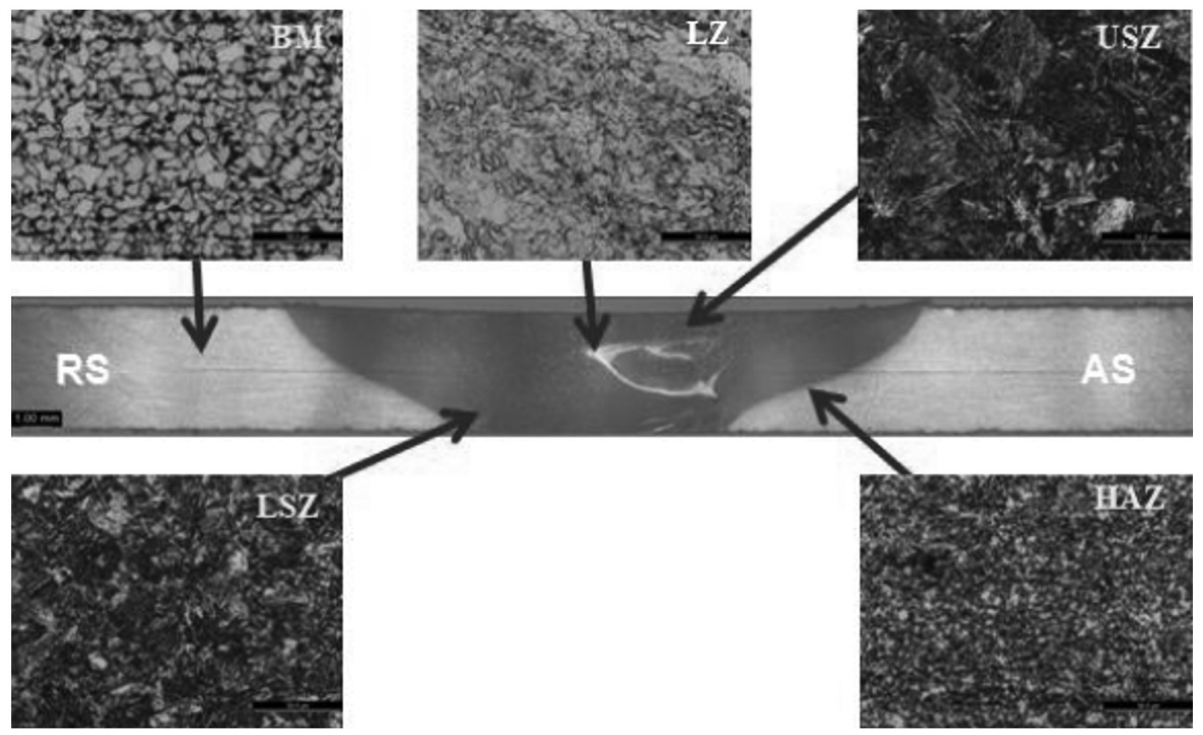

Figure 4. Macro and Micrographs of the weld FSW-PA-LB-548 at the end of the welding joint; BM-base material; LZ - light zone; USZ - upper stirred zone; RS - retreating side; AS - advancing side; LSZ - lower stirred zone; $\mathrm{HAZ}$ - heat affected zone.

The microstructure is mainly composed of fine equiaxed ferrite with a small amount of pearlite which is in agreement with previous work (Konkol et al. [4] and Konkol and Mruczek [13]).In the heat-affected zone (HAZ) it was possible to observe a more homogeneous refined region, compared to the base material, with a darker coloration. This dark colour of the microstructure extends into the stirred zone, where some banded features are observed. According to Reynolds et al. [3] a comparison indicates that the microstructure of the stirred zone is mainly constituted of bainite and martensite. The light structure in the middle of the stirred zone has a random distribution along the macrograph with no apparent orientation, with two main colorations (related to the two types of structure) in approximately the same proportion, with dispersed aggregates. This microstructure may be related to the fact that the steel plate was painted with a red primer, used in shipbuilding, before the welding process. Since it is a zinc based primer, it is acceptable to assume that the melting point of the primer is more or less the same of zinc $\left(419.58^{\circ} \mathrm{C}\right)$. In a typical temperature profile of FSW of steel (Figure 5), the peak temperatures behind the tool are well above the melting point of zinc.

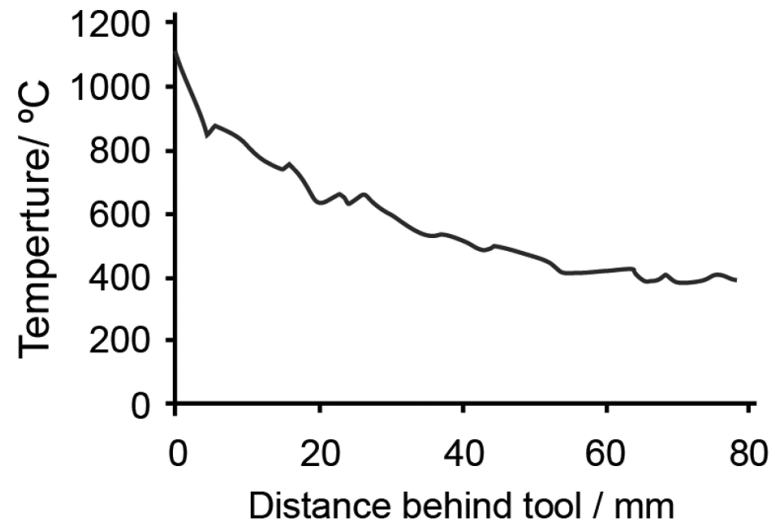

Figure 5. FSW Temperature measurements of a low carbon $12 \%$ chromium steel [9]. 
Since steel has very high thermal conductivity, it can be assumed that there is a temperature rise in the front of the tool. These effects cause the paint to be eliminated during welding and eventually might have led to a reaction between chemical elements of the primer and the base materials, creating not only the microstructure observed always in the advancing side, but also might have promoted some intermetallic formation between the primer and the base material, affecting the properties of the steel.

In order to characterize this region and understand some of the differences observed in the microstructures, an energy dispersive spectroscopy (EDS) analysis of the chemical elements in the welded zones was performed. For this, a sample was taken at the end of the weld FSW-PA-LB-548, and an EDS scan was run in the three regions identified (Figure 6). The results were compared in order to establish a relationship between the observed microstructures and the chemical composition.

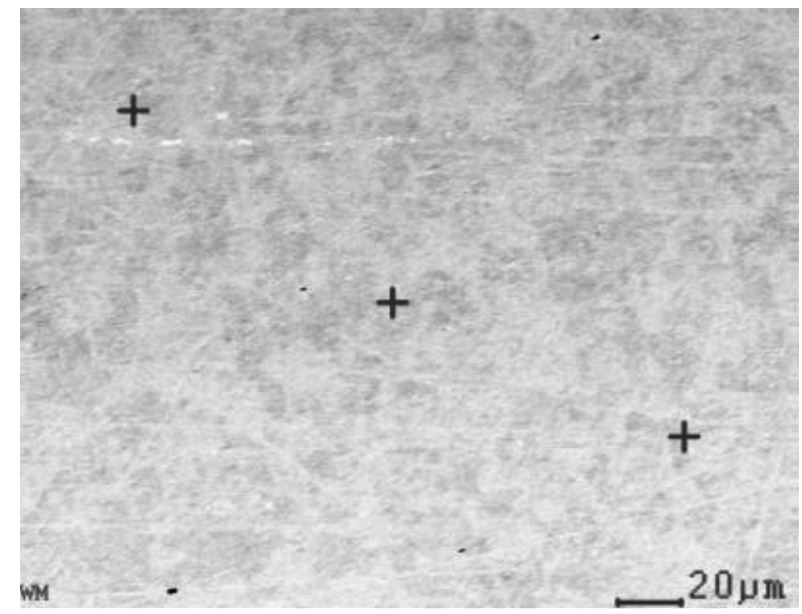

Figure 6. Location of the points chosen to perform the EDS analysis in the base material of FSW-PA-LB-548 joint.

The regions selected for EDS analysis were: the base material (which was used to compare the results with a chemical analysis performed on the steel plate, Figure 6), the stirred zone (it was assumed that the chemical composition of the stirred zone was constant along the thickness, Figure 7) and the white region in the stirred zone (Figure 7). Figure 6 shows the three points used to measure the chemical composition of the base material. Figure 7 shows the line drawn to assess the chemical composition of the stirred zone, identified by SZ, and the white region, identified by WR.

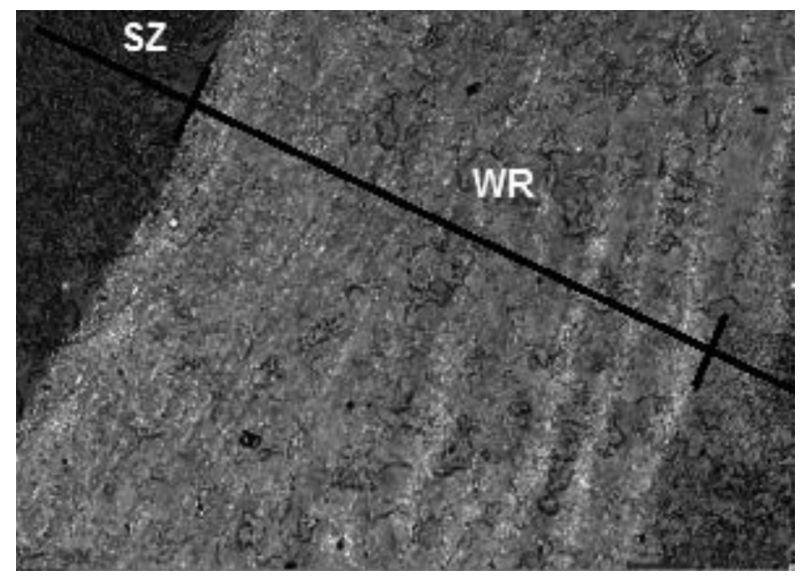

Figure 7. Cross line for EDS analysis through the stirred zone and the light region observed at the end of the weld FSW-PA-LB-548. 
In order to evaluate the previous assumption, the weight percentage of identified elements along the line was registered, as well as the content of zinc. However, the EDS analysis has a limitation regarding the atomic number of identifiable elements sit is not possible to obtain real values of weight percentage for elements with atomic number below eight as carbon. Thus, only a qualitative analysis of the carbon content can be done. Thus, the methodology adopted was to compare the results of the other elements with the results of the chemical analysis. With these a correlation factor was established between the values obtained in the EDS analysis and the carbon weight percentage of the base material, stirred zone and the light region under analysis. Tables 4 and 5 show the results of the EDS analysis.

With the results shown in Tables 4 and 5 it was possible to compare the chemical element variation including carbon. The results are presented in Table 6.

Table 4. Average percentage (in wt\%) of the elements analyzed by EDS in the regions selected (weld FSW-PA-LB-548).

\begin{tabular}{cccc} 
Element & \multicolumn{3}{c}{ Average weight \% } \\
& Base material (BM) & Stirred zone (SZ) & White region (WR) \\
$\mathrm{Al}$ & 0.13 & 0.88 & 0.87 \\
$\mathrm{Si}$ & 0.34 & 1.63 & 4.00 \\
$\mathrm{P}$ & 0.04 & 0.67 & 0.68 \\
$\mathrm{~S}$ & 0.17 & 0.86 & 0.87 \\
$\mathrm{Ti}$ & 0.08 & 0.80 & 0.83 \\
$\mathrm{~V}$ & 0.03 & 0.78 & 0.82 \\
$\mathrm{Cr}$ & 0.08 & 0.79 & 0.87 \\
$\mathrm{Mn}$ & 1.42 & 2.20 & 2.29 \\
$\mathrm{Fe}$ & 93.47 & 79.22 & 78.23 \\
$\mathrm{Ni}$ & 0.03 & 0.87 & 1.04 \\
$\mathrm{Cu}$ & 0.18 & 0.69 & 0.70 \\
$\mathrm{Zn}$ & 0 & 0.56 & 0.85 \\
\hline
\end{tabular}

Table 5. Comparative carbon relation given by the EDS scan after analyzingthe regions selected (weld FSW-PALB-548) BM- Base material, SZ-Stirred Zone, WR-White region.

\begin{tabular}{ccc}
\hline \multicolumn{3}{c}{ Comparative carbon relation } \\
BM & SZ & WR \\
4.04 & 10.05 & 7.74 \\
\hline
\end{tabular}

Table 6. Variation in \% of the average chemical composition analyzed on EDS scan in the regions selected (weld FSW-PA-LB-548)BM- Base material, SZ-Stirred Zone, WR-White region.

\begin{tabular}{cccc}
\hline Element & & Variation in $\%$ & \\
& BM-SZ & BM-WR & SZ-WR \\
$\mathrm{C}$ & $149 \%$ & $97 \%$ & $-21 \%$ \\
$\mathrm{Al}$ & $580 \%$ & $571 \%$ & $-1 \%$ \\
$\mathrm{Si}$ & $381 \%$ & $1076 \%$ & $145 \%$ \\
$\mathrm{P}$ & $1573 \%$ & $1598 \%$ & $2 \%$ \\
$\mathrm{~S}$ & $404 \%$ & $413 \%$ & $2 \%$ \\
$\mathrm{Ti}$ & $898 \%$ & $934 \%$ & $4 \%$ \\
$\mathrm{~V}$ & $2500 \%$ & $2649 \%$ & $6 \%$ \\
$\mathrm{Cr}$ & $884 \%$ & $989 \%$ & $11 \%$ \\
$\mathrm{Mn}$ & $55 \%$ & $62 \%$ & $4 \%$ \\
$\mathrm{Fe}$ & $-15 \%$ & $-16 \%$ & $-1 \%$ \\
$\mathrm{Ni}$ & $2804 \%$ & $3370 \%$ & $20 \%$ \\
$\mathrm{Cu}$ & $281 \%$ & $288 \%$ & $2 \%$ \\
$\mathrm{Zn}$ & - & - & $52 \%$ \\
\hline
\end{tabular}


According to Table 6 it is possible to observe that there are significant differences between the three regions identified, in terms of chemical composition, which reinforces the three region division considered.

Starting with the first hypotheses raised, EDS results show an increasing variation of Zinc between the base material with no Zinc to the stirred zone and then to the white region. Although the final value is not very high, the zinc content in the white region is about $0.86 \%$, which represents an increase of $52 \%$ compared to the stirred zone. This means that there is some Zinc in the stirred zone, with a higher concentration in the white region (Figure 7). Nandan et al. [11] studied the material flow in FSW of mild steel. Figure 8 presents a plot of the isothermic curves at the surface of the work piece and it is reasonable to assume that, in fact, some of the primer elements as Zinc entered the base material ahead of the tool and migrated to the stirred zone, with a content depending on the local change of material flow and properties (as viscosity) along the plate thickness.

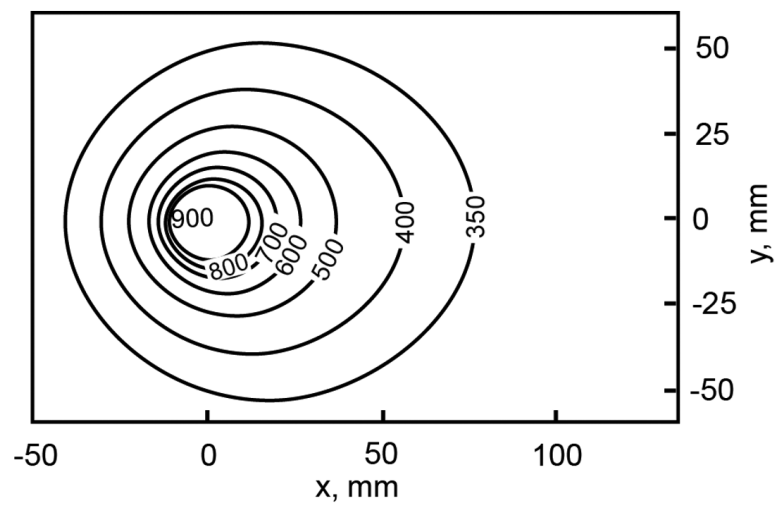

Figure 8. Isothermal lines in FSW of mild steel [4].

Another element exhibiting a similar evolution is $\mathrm{Si}$, with the greatest increase from the stirred zone to the white region. Figure 9 depicts its variation along the line shown in Figure 7.

The remaining of the elements, except carbon, shows about the same values in both the stirred zone and the white region.

The carbon variation along the three zones, as well as, the differences observed between the base material and the stirred zone will be further discussed in the hardness analysis section.

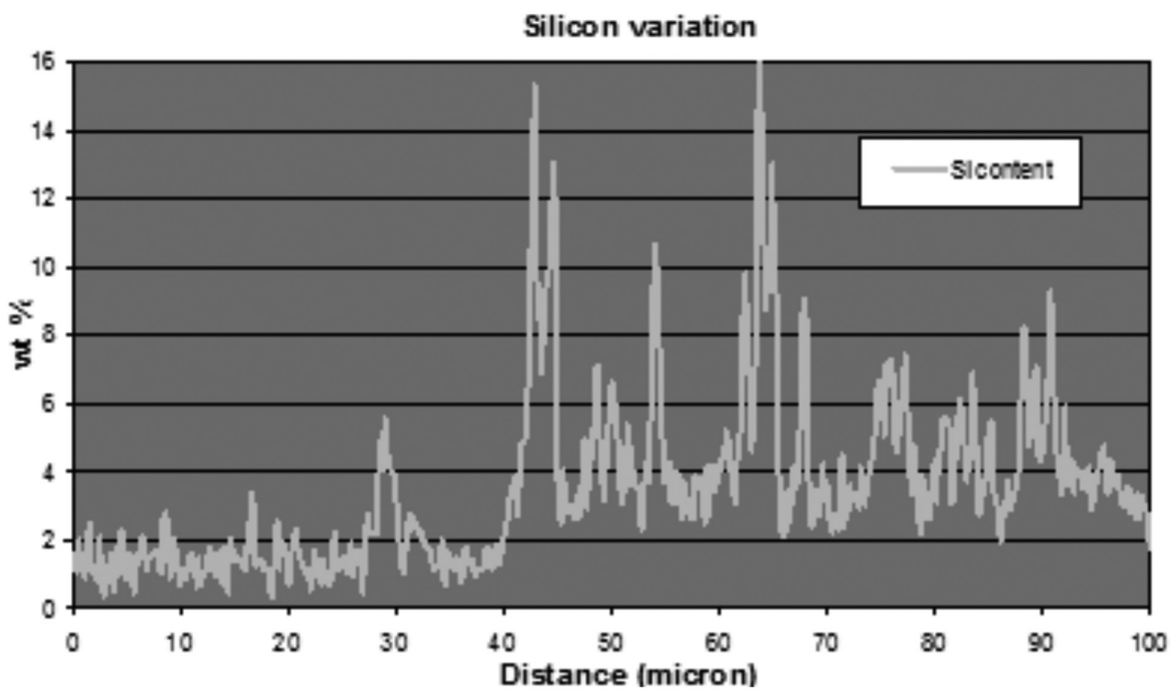

Figure 9. Silicon wt\% along the line shown in Figure 7 scanned by EDS. 


\subsection{Microhardness analysis}

Vickers hardness values measured across the welds are depicted in Figures 10 and 11 and are in accordance with the microstructures identified under microscopy.

The average hardness value presented in both figures corresponds to the base material (168 HV) and is considerably lower than the values measured in the stirred zone ( $363 \mathrm{HV}$ and $415 \mathrm{HV}$, respectively, in samples M1 and M2). The stirred zone has a predominantly bainitic microstructure with some martensite. This high microhardness values are similar to the ones reported by Reynolds et al. [3]. In both samples a sharp increase is observed from the BM to the HAZ with hardness values of around 200-260 HV increasing in the stirred zone, where the mean value is around $340 \mathrm{HV}$ in M1 and $360 \mathrm{HV}$ for M2.

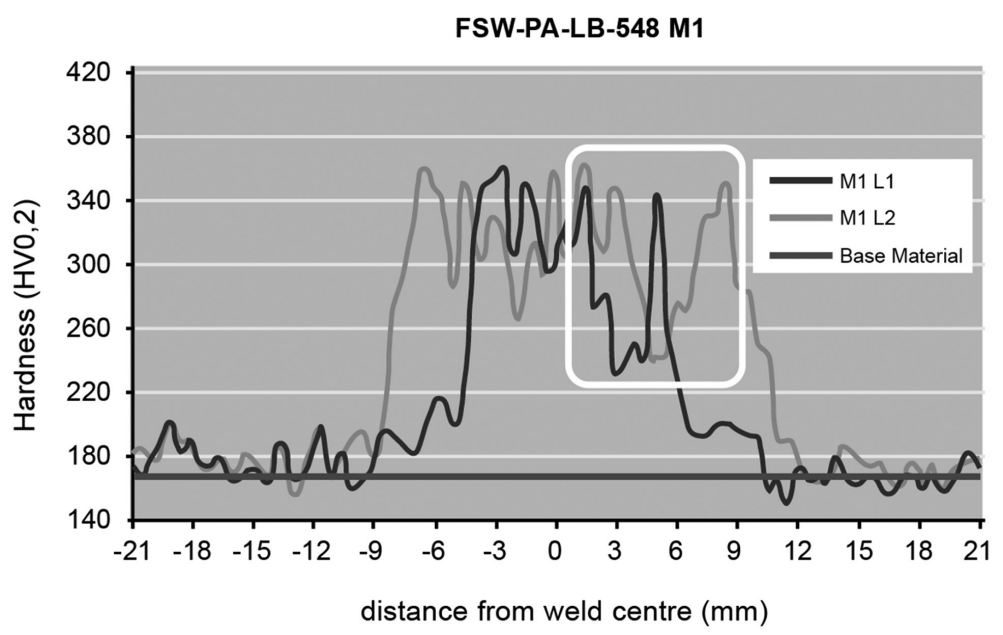

Figure 10. $548 \mathrm{M} 1$ Microhardness profile.

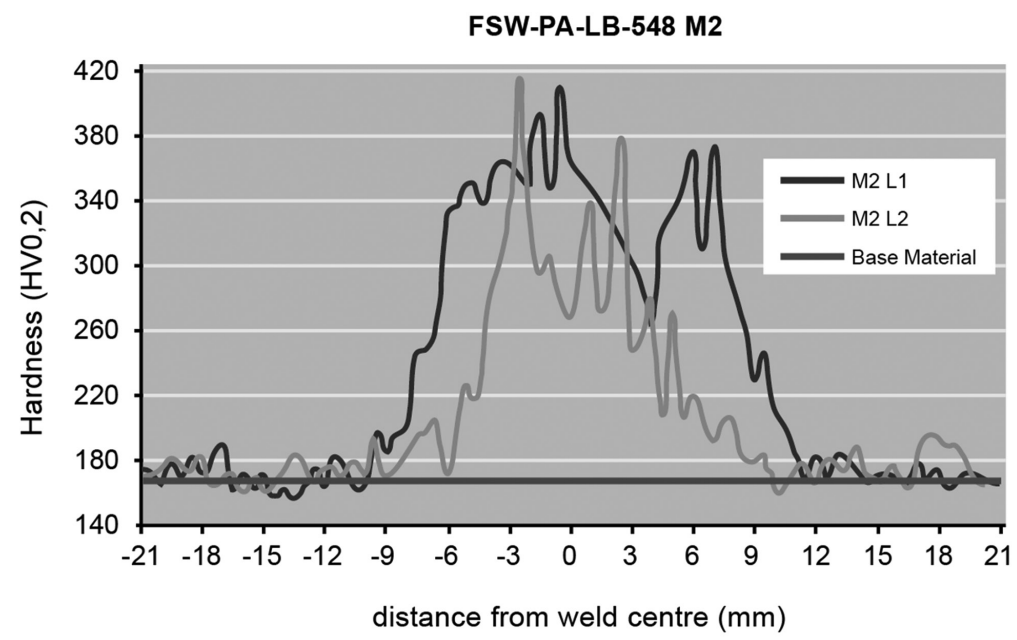

Figure 11. $548 \mathrm{M} 2$ Microhardness profile.

From the base material to the stirred zone, it was observed an increase in the content of elements such as aluminium, chromium, vanadium and carbon which are known to be responsible to increase the steel hardness. Moreover, a significant increase of phosphorous was detected, which is known to have an embrittlement effect. The existence of the primer before welding and the welding parameters used can be responsible for the temperature and the cooling rate promoting the formation of instable brittle phases as martensite and, to a less extent, bainite. In the previously identified light area (Figure 3 and Figure 4), a remarkable decrease in hardness was observed that is related to the carbon content quantitatively measured by EDS in this area. 


\subsection{Tensile tests analysis}

Figure 12 depicts the evolution of nominal force-displacement tensile test curve of the tests performed.

The tensile behaviour is very similar in terms of tensile values and elongation to rupture. The yield stress was in average of $421 \mathrm{MPa}$ and the maximum stress of $521 \mathrm{MPa}$. The elongation to fracture was about 31\% (Table 7). Comparing these results with the nominal mechanical properties for A36 steel available in literature, the values measured are within the requirements for accepting the base material as certificated for shipbuilding (minimum yield stress of $355 \mathrm{MPa}$, UTS between 490 and $630 \mathrm{MPa}$ and minimal elongation of $21 \%$ ). All the specimens fractured in the base material outside the welded region indicating a good mechanical strength of the welded joint.

Table 8 depicts a comparison between the yield and tensile strengths of the base material and the friction stir welded sample confirming the higher mechanical properties of the welded joint.

FSW-PA-LB-548

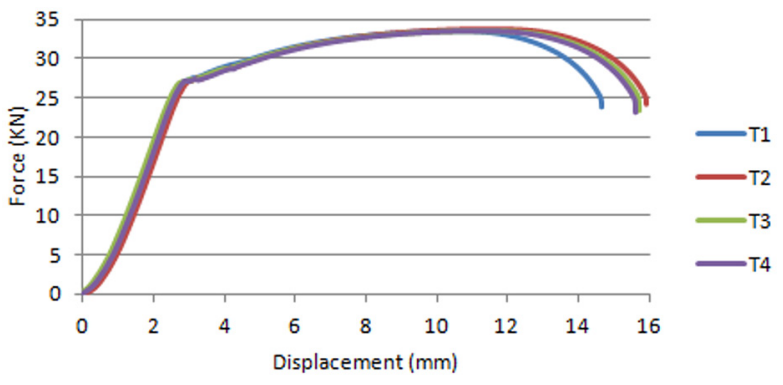

Figure 12. Tensile test results of FSW-PA-LB-548 welded specimens.

Table 7. Main results from the tensile tests of the weld FSW-PA-LB-548.

\begin{tabular}{cccc}
\hline Test & Yield Stress $(\mathbf{M P a})$ & UTS $(\mathbf{M P a})$ & Elongation to fracture $(\%)$ \\
T1 & 423.40 & 521.98 & 29.27 \\
T2 & 421.36 & 522.91 & 31.77 \\
T3 & 419.50 & 520.36 & 31.43 \\
T4 & 419.60 & 519.27 & 31.20 \\
Average & 419.60 & 519.27 & 31.20 \\
\hline
\end{tabular}

Table 8. Summary of tensile tests results.

\begin{tabular}{cccc}
\hline Steel plates & Yield stress (MPa) & UTS (MPa) & Elongation to fracture (\%) \\
FSW-PA-LB-548 & $420.97 \pm 0.44 \%$ & $521.13 \pm 0.31 \%$ & $30.92 \pm 3.63 \%$ \\
CMB & $295.22 \pm 2.13 \%$ & $381.43 \pm 2.43 \%$ & $32.80 \pm 3.48 \%$ \\
\hline
\end{tabular}

\subsection{Fatigue tests analysis}

The fatigue test results are presented in form of S-N curves and compared with Veritas [14] and the Hobbacher [15] standards and, whenever possible, with the results of base material. The DNV reference curve used for the welded joints assessment is the one for fusion welding of steels with $\mathrm{N} \leq 10^{7}$ cycles. In relation with the IIW standards, since there is no specific standard for friction stir welding, fatigue test results of FSW joints were also compared with the fatigue design FAT 112 line, which is the highest limit for fusion welding of steel. Table 9 presents the fatigue test results.

Figure 13 shows the FSW-PA-LB-548 tested specimens and Figure 14 shows the S-N curve representing the experimental results and the respective IIW and DNV reference curves. 
Table 9. Fatigue test results (weld FSW-PA-LB-548).

\begin{tabular}{ccccccccc}
\hline Specimen & $\begin{array}{c}\text { Yield Stress } \\
{[\mathrm{MPa}]}\end{array}$ & $\begin{array}{c}\boldsymbol{\sigma}_{\min } \\
{[\mathbf{M P a}]}\end{array}$ & $\%$ of UTS & $\begin{array}{c}\boldsymbol{\Delta} \boldsymbol{\sigma} \\
{[\mathbf{M P a}]}\end{array}$ & $\begin{array}{c}\text { Frequency } \\
{[\mathbf{H z}]}\end{array}$ & $\begin{array}{c}\text { Number of } \\
\text { Cycles }\end{array}$ & Fracture \\
$548-1$ & & 392.2 & 75 & 353 & 100 & 45300 & Yes \\
$548-2$ & & 366 & 70 & 329.4 & 100 & 38400 & Yes \\
$548-3$ & & 339.9 & 65 & 306 & 100 & 381700 & Yes \\
$548-4$ & 397,79 & 313.7 & 60 & 282.4 & 100 & 1162000 & Yes \\
$548-5$ & & 261.5 & 50 & 235.4 & 100 & 547600 & Yes \\
$548-6$ & & 235 & 45 & 211.6 & 100 & 6500000 & No \\
$548-7$ & & 40 & 188.2 & 100 & 6500000 & No \\
\hline
\end{tabular}
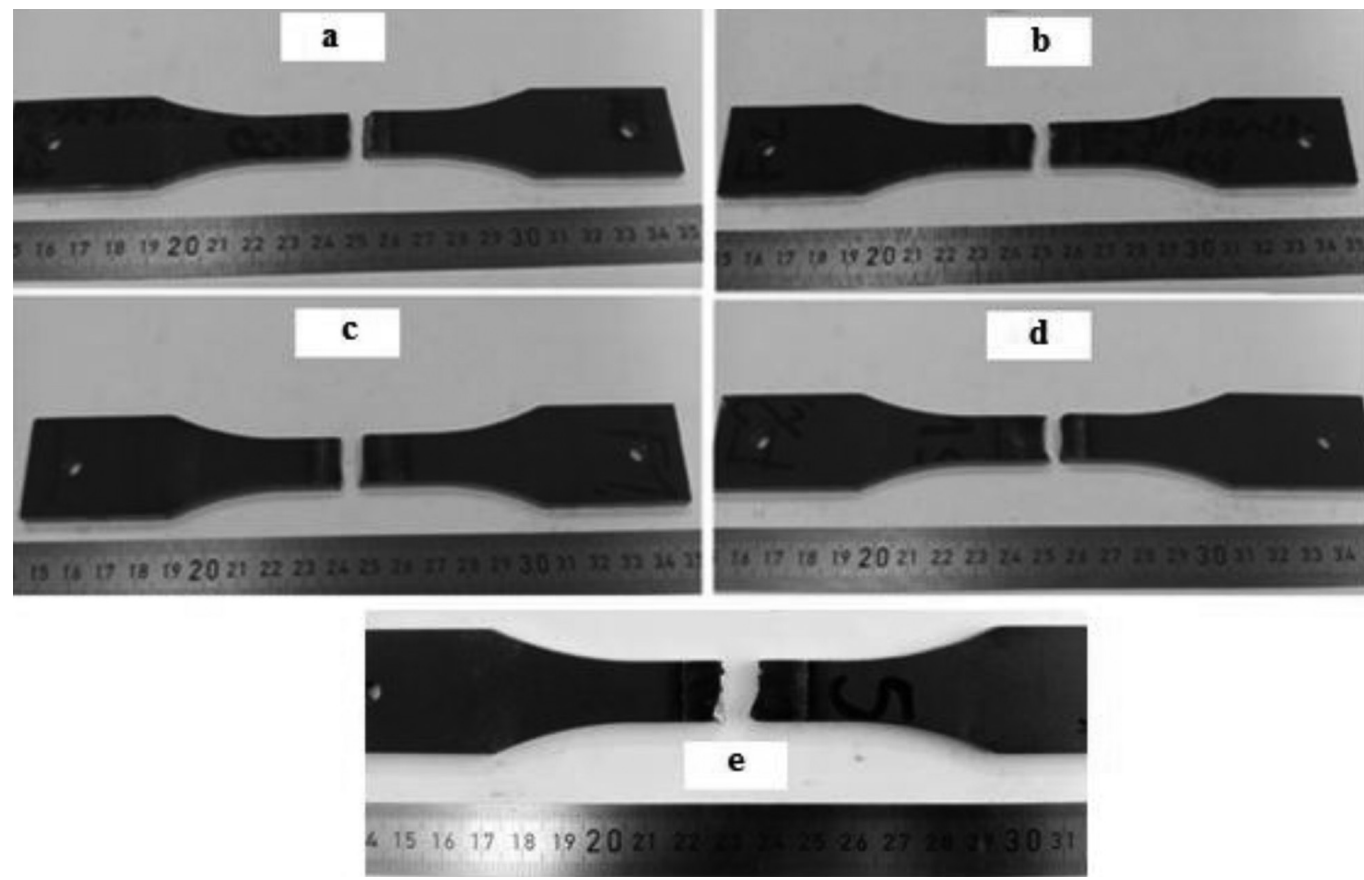

Figure 13. Fatigue test specimens in weld FSW-PA-LB-548: (a) 548-1, (b) 548-2, (c) 548-3, (d) 548-4, (e) 548-5.

FSW-PA-LB-548

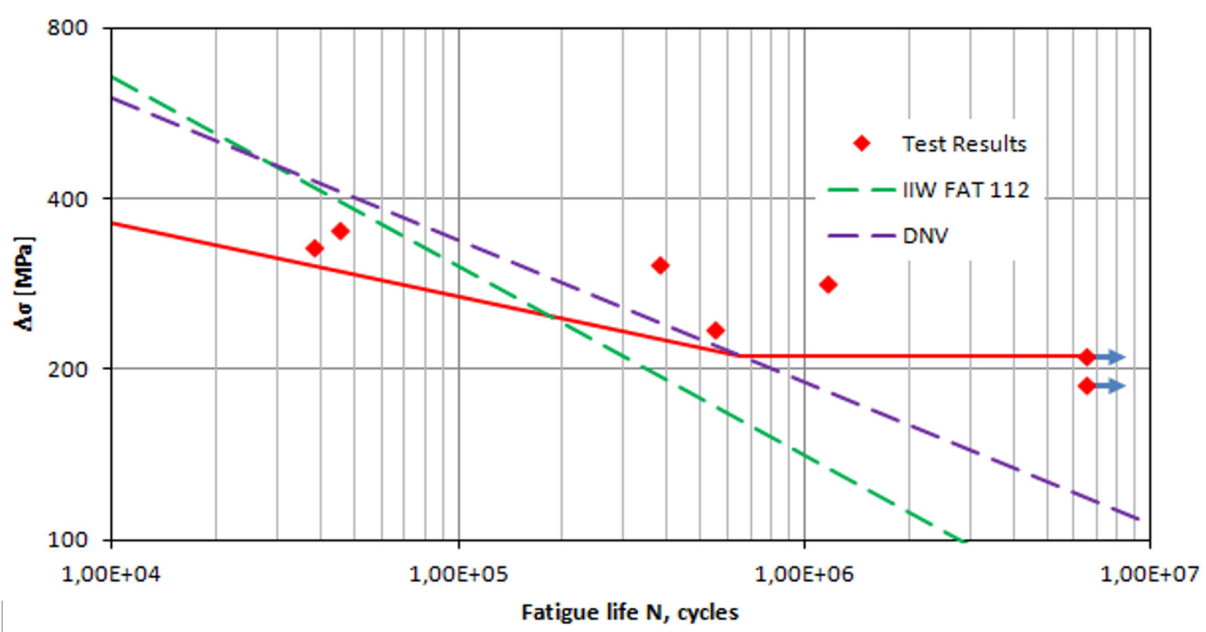

Figure 14. Experimental S-N curve for FSW-PA-LB-548 joint. 
The starting stress range value was the one with $\sigma_{\max }$ correspondent to $40 \%$ of the UTS (from the specimen 548-7 to the specimen 548-1). From that point on, increasing $10 \%$ of the UTS on each step, led to the results plotted in Figure 14.

In relation to IIW and DNV reference lines, it is possible to see that the test results are above the two lines for stress ranges below $212 \mathrm{MPa}$ which indicates a good fatigue strength of the welded joint within the stress values tested. Nevertheless, for higher stress values, the S-N experimental line falls below both the DNV and IIW FAT 112 reference lines.

These results point out that the softer microstructure in the welded joint influenced on the tests with higher stress levels, causing the specimens fracture to occur at a lower number of cycles than the first tests with lower $\Delta \sigma$ would predict. On the other hand, the fine martensitic structure observed is known to be efficient in reducing early crack nucleation, (Lakshminarayanan and Balasubramanian [6]), which may improve the fatigue resistance of welded joints in the referred stress ranges.

Figure 15 shows an overall comparison between the fatigue tests performed in this study and the results from of studies available in the literature.

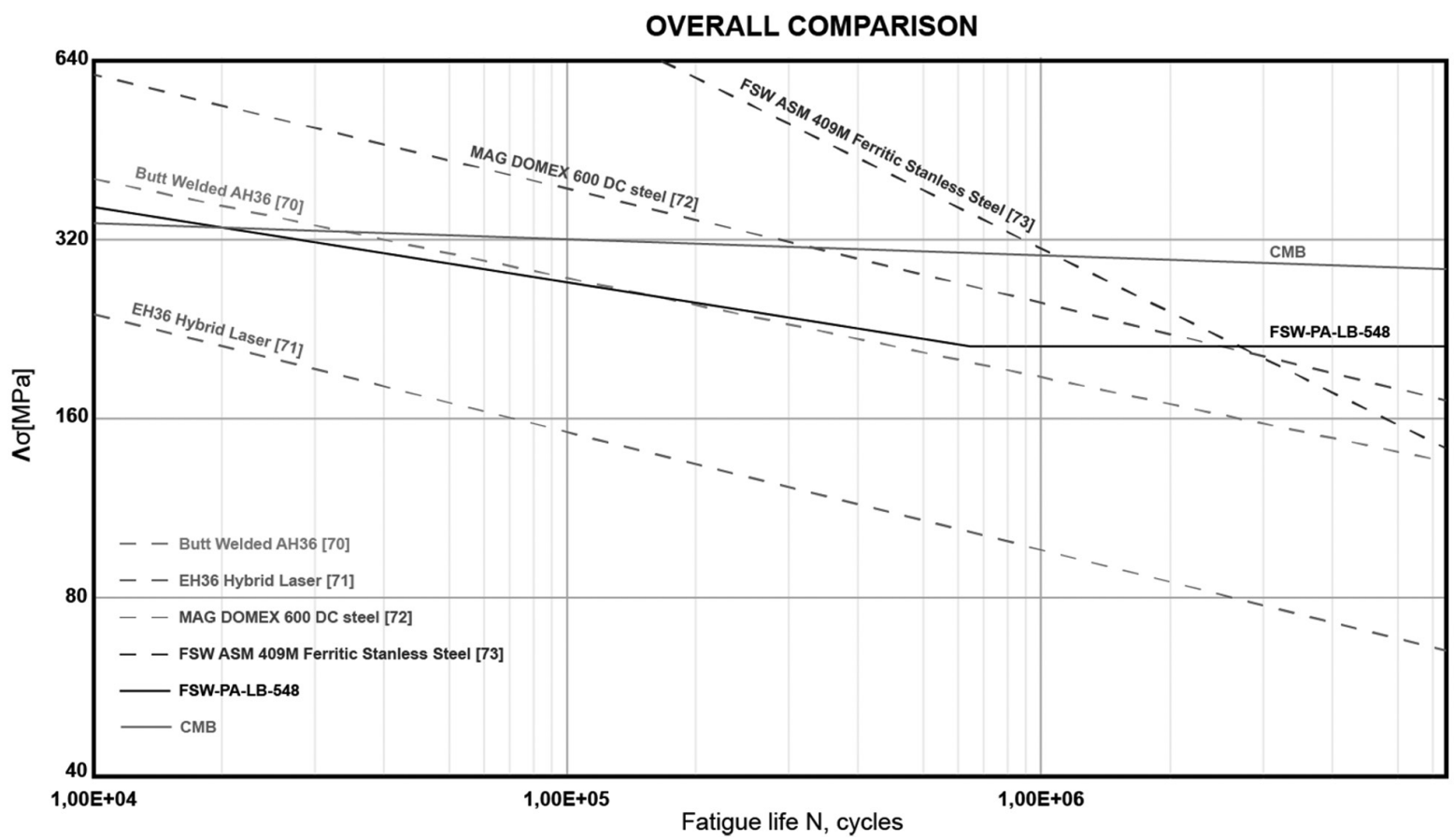

Figure 15. Overall comparison between all the fatigue results performed and fatigue results from other studies regarding different welding processes and/or steels.

Comparing FSW with other studies performed with the same steel (EH36) using fusion welding processes, even with a direct FSW competitor, Hybrid Laser Welding, the results from FSW tests are globally better in terms of fatigue strength, in the stress ranges tested. Regarding the MAG welding process in steel, it is also possible to observe that, although the base material mechanical properties are significantly higher than the ones of the steel used in this study (the DOMEX 600 DC steel has yield stress and UTS values even higher than the stainless steel), the fatigue behaviour of these welded joints has proven to be slightly better and only in stress ranges above approximately $290 \mathrm{MPa}$. This fact reinforces not only the good quality of the results achieved in this work but also the quality of the FSW process. 
Equation 1 and Table 10 summarise the results obtained, where the $\mathrm{m}$ value represents the slope of the $\mathrm{S}-\mathrm{N}$ curve, $\mathrm{b}$ is a constant obtained from the experimental results and the $\mathrm{r}^{2}$ value is a statistical measure of the deviation from the mean curves.

$$
\log N=b-m \times \log \Delta \sigma
$$

Table 10 summarizes the S-N equation coefficients of all the fatigue tests performed and also from other studies found in open literature and it confirms the higher mechanical performance of the solid state welded samples, proving FSW of steel is a process worth considered for industrial applications.

Table 10. S-N equation coefficients of all the fatigue tests performed, as well as of other relevant studies for comparison ( $\mathrm{m}$ - value -slope of the $\mathrm{S}-\mathrm{N}$ curve, b-constant obtained from the experimental results, $\mathrm{r}^{2}$-statistical measure).

\begin{tabular}{lccc}
\hline & $\mathbf{m}$ & $\mathbf{b}$ & $\mathbf{r}^{\mathbf{2}}$ \\
Fusion Welded AH36, Kristensen et al. [16] & 3.000 & 18.700 & Not available \\
EH36 Hybrid Laser, Crupi et al. [17] & 4.808 & 15.468 & Not available \\
MAG DOMEX 600 DC steel, Costa et al. [18] & 5.160 & 18.369 & 0.630 \\
FSW ASM 409M, Lakshminarayanan and Balasubramanian [6] & 2.440 & 12.064 & 0.966 \\
FSW-PA-LB-548 & 7.748 & 23.832 & 0.580 \\
\hline
\end{tabular}

\section{Conclusions}

From this study it was possible to show the feasibility of FSW for welding shipbuilding steel producing good quality welds.

The use of plates in which a primer has been applied before FSW does not have a detrimental effect in the mechanical behaviour of the steel for shipbuilding applications though it influences this.

From the metallurgical perspective, it was possible to identify four different regions in the welded joint: base material, heat-affected zone, lower stirred zone and upper stirred zone. Having been painted before the welding trials, it was observed in the macroanalysis (Figure 3 and Figure 4) a light region with lower carbon content within the stirred zone, possibly originated by the reaction of some chemical compounds of the paint and the base material, with different mechanical properties from the surrounding material.

Microhardness increased from the base material to the stirred zone. The primer greatly influenced the hardness values of the stirred zone. It increased the hardness profiles by altering the welding conditions which led to the appearance of martensite, but also the presence of a different softer microstructure caused by the effect of primer replacing actual steel, can create a stress concentration region.

Regarding the tensile test results, all specimens broke outside the welded region and both yield and UTS showed an increase in welded specimens tested compared to the base material.

In terms of fatigue test results, the specimens were placed above the two IIW and DNV reference standards. None of the specimens tested broke with a maximum stress below $50 \%$ of the UTS. The fatigue properties of the welded specimens showed a high slope of all the S-N curves obtained (Table 10) well above most of the studies found in the literature, performed with different welding processes and even with higher strength steels from stress ranges below $320 \mathrm{MPa}$.

Friction Stir Welding is a suitable technology for shipbuilding since it allows to produce welds with matching fatigue properties in shipbuilding steel with primer.

When compared with alternative fusion welding process, the reduction of fume generation and the more friendly environmental process are important advantages, the reduced heat input also leads to lower distortion, thus minimising the need of reworking. 


\section{References}

[1] Thomas WM, Threadgill PL, Nicholas ED. The feasibility of friction stir welding steel. Science and Tecnhology of Welding and Joining. 1999;4(6):365-372. http://dx.doi.org/10.1179/136217199101538012.

[2] Lienert TJ, Stellwag WL Jr, Grimmett BB, Warke RW. Friction stir welding studies on mild steel. Welding Journal. 2003;1s-9s.

[3] Reynolds AP, Tang W, Posada M, Deloach J. Friction stir welding of DH-36 steel. Science and Technology of Welding and Joining. 2003;8(6):455-460. http://dx.doi.org/10.1179/136217103225009125.

[4] Konkol PJ, Mathers JA, Johnson R, Pickens JR. Frictions stir welding of HSLA-65 steel for shipbuilding. Journal of Ship Production. 2003;19:159-166.

[5] Failla D II. Friction stir welding and mirostructures simulation of HSLA-65 and austenitic stainless steels [doctor thesis]. Ohio: Ohio State University; 2009.

[6] Lakshminarayanan A, Balasubramanian V. Assessment of fatigue life and crack growth resistance of friction stir welded AISI 409M ferritic stainless steel joints. Materials Science and Engineering A. 2012;539:143-153. http://dx.doi.org/10.1016/j. msea.2012.01.071.

[7] Avila JA, Ruchert COFT, Mei PR, Marinho RR, Paes MTP, Ramirez AJ. Fracture toughness assessment at different temperatures and regions within a friction stirred API $5 \mathrm{~L}$ X80 steel welded plates. Engineering Fracture Mechanics. 2015;147:176-186. http://dx.doi.org/10.1016/j.engfracmech.2015.08.006.

[8] McPherson NA, Galloway AM, Wood J, Cater SR. A comparison between single sided friction stir welded and submerged arc welded DH36 steel thin plate. In: Proceedings of the 9th International Conference on Trends in Welding Research; Chicago, United States; 2013. p. 291-296.

[9] Azevedo, J., Infante, V., Quintino, L., Santos, J. Fatigue behaviour of friction stir welded steel joints. Advanced Materials Research.
2014;891-892:1488-1493. http://dx.doi.org/10.4028/www. scientific.net/AMR.891-892.1488.

[10] Pandey KN, Gupta SK. Fatigue crack growth analysis of mild steel plate welded by friction stir welding. In: Proceedings of the ASME International Mechanical Engineering Congress and Exposition; 2013 November 15-21; San Diego, California, USA: ASME; 2013.v. 9. http://dx.doi.org/10.1115/IMECE2013-63163.

[11] Nathan SR, Balasubramanian V, Malarvizhi S, Rao AG. Effect of welding processes on mechanical and microstructural characteristics of high strength low alloy naval grade steel joints. Defence Technology. 2015;11(3):308-317. http://dx.doi. org/10.1016/j.dt.2015.06.001

[12] Azevedo J. Fatigue behavior of friction stir welded shipbuilding steel joints [master dissertation]. Lisboa: Instituto Superior Técnico, Universidade Técnica de Lisboa; 2012.

[13] Konkol PJ, Mruczek MF. Comparison of friction stir weldments and submerged arc weldments in HLSA-65 steel. Welding Journal. 2007;187-s-195-s.

[14] Veritas DN. Fatigue assessment of ship structures. Høvik, Norway: DNV; 2010.

[15] Hobbacher A. Recommendations for fatigue design of welded joints and components. New York: Springer; 2008. (IIW Collection).

[16] Kristensen J, Webster S, Petring D. Hybrid laser welding of thick section steels -The HYBLAS project. In: Proceedings of the 12th NOLAMP Conference. Copenhagen; 2009.

[17] Crupi V, Guglielmino E, Maestro M, Marinò A. Fatigue analysis of butt welded AH36 steel joints: Thermographic Method and design S-N curve. Marine Structures. 2009;22(3):373-386. http:// dx.doi.org/10.1016/j.marstruc.2009.03.001.

[18] Costa J, Ferreira J, Abreu L. Fatigue behaviour of butt welded joints in a high strength steel. Procedia Engineering. 2010;2(1):697705. http://dx.doi.org/10.1016/j.proeng.2010.03.075. 